Leading Article

\title{
Competitive sport and the insulin-dependent diabetic patient
}

\author{
P.M. Greenhalgh
}

Academic Department of Diabetes, Whittington Hospital, London N19, UK.

Many insulin dependent diabetic patients have competed, against the odds, at national or international level in strenuous sports. The increase in psychological wellbeing ${ }^{1-3}$ and in insulin sensitivity in both Type $\mathrm{I}^{4-6}$ and Type II diabetic subjects ${ }^{5,7,8}$ with moderate exercise have been well documented, as has the improvement in lipid profile ${ }^{6,8.9}$ and mild to moderate hypertension. ${ }^{10}$ But earlier theories that exercise improves metabolic control in Type I diabetes ${ }^{11}$ have now been challenged, ${ }^{12,13}$ and strenuous exercise is not without its risks. Proliferative retinopathy may progress to retinal haemorrhage, ${ }^{14,15}$ and proteinuria increases with exercise $^{16}$ (though this may not be of pathological significance ${ }^{15}$ ). Even mild peripheral neuropathy greatly increases the risk of soft tissue injury, particularly to the feet. ${ }^{15}$ Autonomic neuropathy, as well as reducing the cardiovascular response to exercise ${ }^{15,17}$ impairs the response to overheating and dehydration. ${ }^{15}$ However, the most immediate risks to the diabetic athlete are metabolic. Exercise increases both the risk of hypoglycaemia in the hyperinsulinaemic subject ${ }^{15,18}$ and that of ketosis in the insulin deficient subject. ${ }^{19,20}$ In order to give sensible advice on diet and insulin regimens to the diabetic athlete, an understanding of the metabolic basis of physical exercise is necessary.

\section{The metabolic basis of physical exercise in diabetes}

Circulating blood glucose accounts for only a tiny percentage $(80 \mathrm{kcal})$ of stored energy, compared with liver glycogen $(300 \mathrm{kcal})$, muscle glycogen $(1500 \mathrm{kcal})$, and adipose tissue $(150,000 \mathrm{kcal}) .^{19}$ However, the blood glucose level is a dynamic variable, influenced by changes in both its rate of consumption and its rate of production. At rest, over $90 \%$ of muscle energy is derived from the oxidation of fatty acids. ${ }^{19}$ With increasing exercise intensity, the contribution of circulating blood

Correspondence: P.M. Greenhalgh, B.A., B.M., B.Ch., M.R.C.P.

Received: 25 April 1990 glucose to muscle energy supply increases both absolutely and relatively, from about $1-2 \mathrm{mmol} /$ $\mathrm{min}(5 \%$ of total energy) at rest to $30 \mathrm{mmol} / \mathrm{min}$ or more $(40 \%$ of total energy) during moderate exercise. ${ }^{19}$ When exercise intensity approaches maximum aerobic capacity $\left(\mathrm{VO}_{2} \mathrm{max}\right)$, almost $100 \%$ of energy is derived from circulating blood glucose. ${ }^{15}$ The massive increase in peripheral glucose uptake in these circumstances is matched by an increase in glucose production - chiefly from hepatic glycogenolysis ${ }^{21}$ - so that in the normal subject, blood glucose levels stay constant and may even rise during short term heavy exercise. ${ }^{19}$

It is important to note that, for both normal and diabetic subjects, the rate of glucose uptake by exercising muscle is determined by the rate of glucose utilization and not by the prevailing free insulin level. ${ }^{21-23}$ In the normal subject, the hormonal response to exercise is geared not to stimulating glucose uptake by the contracting muscle but to mobilizing fuel for the contracting muscle. ${ }^{23,24}$ The onset of exercise produces a rapid rise in serum catecholamine levels, ${ }^{24-26}$ which stimulate hepatic glycogenolysis, muscle glycogenolysis and lipolysis both directly ${ }^{21}$ and via alpha-adrenergic inhibition of insulin production and insulin action. ${ }^{24,27,28}$ Serum free insulin levels fall to about one-fifth of pre-exercise levels, ${ }^{24,29}$ stimulating glycogenolysis and lipolysis. Serum glucagon levels may fall during brief exercise $\mathrm{e}^{24}$ but rise in prolonged exercise ${ }^{24,25}$ further promoting hepatic glycogenolysis and gluconeogenesis. The counter-regulatory effects of growth hormone and cortisol may also be important, particularly in prolonged exercise. ${ }^{25}$

The peripheral hyperinsulinaemia which is a feature of Type I diabetes ${ }^{30}$ is made relatively worse by exercise ${ }^{29-31}$ since the normal dramatic fall in insulin output at the onset of exercise does not occur ${ }^{29}$ Exercise may even enhance insulin absorption by increasing subcutaneous blood flow to the insulin injection site,,$^{32-34}$ though the extent of this effect may have been overestimated in the past. ${ }^{13,35}$ Shifting the insulin injection site to a non-exercising part of the body such as the abdomen probably makes little difference to insulin absorption. ${ }^{13,35,36}$ Many Type I diabetic subjects have 
deficient glucagon production, ${ }^{31}$ though this is probably of little clinical significance as long as the catecholamine response is preserved. ${ }^{24,31,37}$ Even in the presence of high levels of all the counterregulatory hormones, a high free insulin level is a powerful inhibitor of glycogenolysis, gluconeogenesis and lipolysis. ${ }^{31}$ In the hyperinsulinaemic state, muscle glucose uptake is unimpaired but glucose mobilization is low and the muscle deprived of glucose cannot simply shift to burning fat.

Therefore, exercise should occur not necessarily when blood glucose levels are high, but when free insulin levels are low. In a state of mild insulin deprivation (omission of subcutaneous insulin for 24 hours) the Type I diabetic subject can produce a rise in blood glucose and serum free fatty acids with exercise which is not significantly different from that of a non-diabetic subject. ${ }^{26,33}$ It is, however, common knowledge that in the poorly-controlled diabetic subject, exercise can make matters worse, leading to rapid and dramatic rises in blood glucose, lactate and ketones. ${ }^{13,19,38-40}$ Until fairly recently, it was thought that this deterioration in control was due to the fall in plasma free insulin levels to below the so-called 'permissive' level required for muscle glucose uptake. ${ }^{19,20,33}$ However, more recent experiments have shown that the isolated perfused rat muscle is capable of increasing glucose transport in virtually insulin-free conditions. ${ }^{13,40}$ The in vivo decrease in glucose uptake by the exercising muscle during ketosis is probably attributable to the presence of high levels of free fatty acids which inhibit glucose uptake via the 'glucose fatty acid cycle'. ${ }^{13}$ In addition, poorly controlled diabetic subjects have catecholamine levels up to 8 times higher than normal subjects or well-controlled diabetic subjects. ${ }^{37}$ These levels, in the presence of insulin deficiency, enhance lipolysis and hence free fatty acid supply to the liver, encouraging ketone body formation. ${ }^{13}$ Many diabetic athletes like to 'run high' to reduce the risk of hypoglycaemia; this should be discouraged. The tighter the background level of diabetic control, the safer it will be to cut back on the amount of insulin taken before a heavy bout of exercise. ${ }^{1,41,42}$

With the increasing popularity of 'endurance sport', events lasting two hours or more are not uncommon. As duration of exercise increases, liver glycogen stores become depleted and fat is used as the main fuel ${ }^{43,44}$ Even in non-diabetic subjects, the blood glucose level may fall ${ }^{45}$ and it is at this point when the liver has no more to give - that the diabetic athlete is doubly at risk of hypoglycaemia. There are several ways of minimizing this risk. First, both the amount of carbohydrate that can be stored as glycogen and the rate of fatty acid utilization during exercise can be increased dramatically with endurance training. ${ }^{26,44,46}$ This has been demonstrated in diabetic as well as non-diabetic athletes. $^{26,47,48}$ The aspiring marathon runner with diabetes must embark upon a steadily-increasing programme of training for several months before the race. Second, a high carbohydrate diet and 'carbohydrate loading' the day before a long event will further boost glycogen stores, ${ }^{44,46}$ and diabetes is no bar to such a practice..$^{47,48}$

\section{Practical considerations}

It is probably reasonable to refer all diabetic athletes over 35 years for formal exercise testing to exclude clinically silent cardiovascular disease. ${ }^{49}$ Proliferative retinopathy is an absolute, and peripheral or autonomic neuropathy a relative, contraindication to strenuous exercise. A background of tight metabolic control is essential for both performance and safety; anything more than mild exercise should not be undertaken in the presence of ketonuria. The diabetic runner should seek professional advice on footwear and attend a chiropodist regularly.

Variations in the duration and intensity of exercise, and its timing in relation to meals and insulin, will lead to variations in glycaemic response to exercise that are not easy to predict. Absorption of ingested carbohydrate may be delayed during exercise even in normal subjects, ${ }^{50,51}$ diabetic athletes are at even greater risk of gastric stasis and vomiting. ${ }^{52}$ One third of 'hypoglycaemic' episodes are not associated with a low blood glucose ${ }^{53}$ and the physical and psychological effects of competitive sport may mimic the symptoms of neuroglycopaenia. ${ }^{1,13}$ For all these reasons, the importance of regular blood glucose monitoring and of 'trial runs' before major events cannot be overestimated. Glucose should, of course, be carried at all times and a medical identity bracelet is a sensible precaution.

Short-term exercise of mild to moderate intensity can usually be covered by extra carbohydrate beforehand (and sometimes afterwards). ${ }^{20}$ As a general rule, the longer the duration and the greater the intensity of exercise, the less oral carbohydrate can be relied upon to maintain euglycaemia. Exercise should occur when free insulin levels are low. If the subject exercises in close proximity to the insulin injection, drastic reductions in dose are needed, of up to $80 \%$ of intermediate-acting insulin and $100 \%$ of soluble insulin. ${ }^{13,20}$ Altering the injection site to the abdomen will probably make little difference to control.

The increased energy requirements of endurance sport are frequently underestimated by physicians and dieticians more used to sedentary patients. A 4-hour marathon at $70 \% \mathrm{VO}_{2} \max$ will require over $500 \mathrm{~g}$ of extra carbohydrate ${ }^{44}$ and much of this can 
be taken in the days preceding the race, along with an appropriate increase in short-acting insulin. ${ }^{1}$ It is also important to reduce post-race insulin and increase carbohydrate after any glycogen-depleting exercise since the replenishing of glycogen stores will increase insulin sensitivity. ${ }^{3,18}$ The hypoglycaemia following prolonged intense exercise can be severe and prolonged, ${ }^{18}$ and should be anticipated.

It has been argued persuasively that if metabolic control has been optimized by careful adjustment of insulin delivery and food intake, addition of exercise to the regimen can only be expected to result in deterioration of metabolic control. ${ }^{13}$ Nevertheless, some of our diabetic patients will take up strenuous sport and a few will excel. The doctor's role is not to prohibit such activity but to advise on the safest way of going about it. The patient's participation in his or her own care is vital to the success of any complex treatment regimen. For the diabetic athlete this requires an understanding of the metabolic basis of both the diabetes and the sport.

\section{References}

1. Berger, M. \& Lefebvre, P. Is exercise beneficial to patients with Type I diabetes mellitus? - Transcript of a controversy debate. In: Berger, M., Christacopoulos, P. \& Wahren, J. (eds) Diabetes and Exercise - Proceedings of a Symposium. Hans Huber, Bern, 1980, pp. 104-114.

2. Divekar, M.V. Yoga therapy as an exercise in diabetes mellitus. In: Berger, M. Christacopoulos, P. \& Wahren, J. (eds) Diabetes and Exercise - proceedings of a Symposium. Hans Huber, Bern, 1980, pp. 179-180.

3. Hillson, R.M. Diabetes Outward Bound mountain course, Eskdale, Cumbria. Practical Diabetes 1984, May: 59-63.

4. Lawrence, R.H. The effects of exercise on insulin action in diabetes. $\mathrm{Br} M e d J$ 1926, 1: 648-652.

5. Grigorescu, F. The metabolic and hormonal response to repeated moderate exercise in diabetic man. In: Berger, $\mathbf{M}$. Christacopoulos, P. \& Wahren, J. (eds) Diabetes and Exercise - proceedings of a Symposium. Hans Huber, Bern, 1980, pp. 95-96.

6. Costill, D.L., Cleary, P., Fink, W.J., Foster, C., Ivy, J.L. \& Witzmann, F. Training adaptations in skeletal muscle of juvenile diabetics. Diabetes 1979, 28: 818-822.

7. Berglung, B., Wajngot, A. \& Efendic, S. Decreased physical working capacity as an additional factor in the pathology of maturity-onset diabetes. In Berger, M., Christacopoulos, P. \& Wahren, J. (eds) Diabetes and Exercise - proceedings of a Symposium. Hans Huber, Bern, 1980, pp. 176-177.

8. Koivisto, V.A. \& De Fronzo, R.A. Exercise in the treatment of Type II diabetes. Acta Endocrinol 1984, 262 (Suppl.): 107-111.

9. Ruderman, N.B., Ganda, O.P. \& Johansen, K. The effect of physical training on glucose tolerance and plasma lipids in maturity-onset diabetes. Diabetes 1979, 28 (Suppl. 1): 89-92.

10. Ruderman, N.B., Schneider, S. \& Kramsch, D. Physical training and cardiovascular disease in the diabetic. In: Berger, M., Christacopoulos, P. \& Wahren, J. (eds) Diabetes and Exercise - proceedings of a Symposium. Hans Huber, Bern, 1980, pp. 166-170.

11. Joslin, E.P., Root, H.F., White, P. \& Marble, A. (eds) Treatment of Diabetes Mellitus. Lea \& Febinger, Philadelphia, 1959.

12. Zinman, B., Zuniga-Guasardo, S. \& Kelly, D. Comparison of the acute and long term effects of physical training on glucose control in Type I diabetes. Diabetes Care 1984, 7: 515-519.

13. Richter, E.A. \& Galbo, H. Diabetes, insulin and exercise. Sports Med 1986, 3: 275-288.

14. McMillan, D.E. Exercise and diabetic microangiopathy. Diabetes 1979, 28 (Suppl. 1): 103-106.

15. Horton, E.S. Role and management of exercise in diabetes mellitus. Diabetes Care 1988, 11: 201-211.

16. Morgensen, C.E. \& Vittinghus, E. Urinary albumin excertion during exercise in juvenile diabetics. Scand J Clin Lab Invest 1975, 35: 295-300.
17. Hilsted, J. \& Galbo, H. Haemodynamics during graded exercise in juvenile diabetics with and without autonomic neuropathy. In: Berger, M. Christacopoulos, P. \& Wahren, J. (eds) Diabetes and Exercise - proceedings of a Symposium. Hans Huber, Bern, 1980, p. 93.

18. MacDonald, M.J. Post-exercise late onset hypoglycaemia in insulin dependent diabetic patients. Diabetes Care 1987, 10: 584-588.

19. Wahren, J. Substrate metabolism during exercise in normal and diabetic man. In: Berger, M., Christacopoulos, P. \& Wahren, J. (eds) Diabetes and Exercise - proceedings of a Symposium. Hans Huber, Bern, 1980, 57-68.

20. Kemmer, F.W. \& Berger, M. Exercise and diabetes mellitus. Int J Sports Med 1983, 4: 77-78.

21. Felig, P. \& Wahren, J. Fuel homeostasis in exercise. N Engl J Med 1975, 293: 1078-1084.

22. Richter, E.A., Kiens, B., Mizuno, M. \& Strange, S. Immobilisation decreases insulin-induced, but not exercise-induced muscle glucose uptake. Diabetologia 1988, 535A-536A.

23. Berger, M., Hagg, S.A. \& Ruderman, N.B. Glucose metabolism in perfused skeletal muscle: interaction of insulin and exercise on glucose uptake. Biochem J 1975, 146: 231-238.

24. Galbo, H. Hormonal and Metabolic Adaptation to Exercise. Georg Thieme, Stuttgart, New York, 1983.

25. Galbo, H. Endocrinology and metabolism in exercise. In: Berger, M., Christacopoulos, P. \& Wahren, J. (eds) Diabetes and Exercise - proceedings of a Symposium. Hans Huber, Bern, 1980, 26-44.

26. Koivisto, V.A., Hendler, R., Nadel, E. \& Felig, P. Influence of physicial training on the fuel-hormone response to prolonged low intensity exercise. Metabolism 1982, 31: 192-197.

27. Soman, V.J., Koivisto, V.A., Diebert, D., Felig, P. \& DeFronzo, R.A. Increased insulin sensitivity and insulin binding to monocytes after physical training. $N$ Engl $J$ Med 1979, 301: $1200-1204$

28. Hartley, L.H., Mason, J.W., Hogan, R.P. et al. Multiple hormone responses to graded exercise in relation to physical training. J Appl Physiol 1972, 33: 602-605.

29. Kemmer, F.W., Berchtold, P., Berger, M. et al. Exerciseinduced fall in blood glucose in insulin-treated diabetics unrelated to alterations in insulin mobilisation. Diabetes 1979, 28: $1131-1137$.

30. Zinman, B., Marliss, E.B. \& Vranic, M. Peripheral insulinaemia and the glucoregulatory response to exercise in diabetic man. In: Berger, M. Christacopoulos, P. \& Wahren, J. (eds) Diabetes and Exercise - proceedings of a Symposium. Hans Huber, Bern, 1980, 45-56.

31. Cryer, P.E., White, N.H. \& Santiago, J.V. The relevance of glucose counterregulatory systems to patients with insulin dependent diabetes mellitus. Endocrine Rev 1986, 7: 131 - 139. 
32. Dandona, P., Hooke, D. \& Bell, J. Exercise and insulin absorption from subcutaneous tissue. $\mathrm{Br}$ Med J 1978, 1: 479-480.

33. Vranic, M. \& Berger, M. Exercise and diabetes mellitus. Diabetes 1979, 28: 147-163.

34. Berger, M., Halban, P.A., Assal, J.P., Offord, R.E., Vranic, M. \& Reynold, A.E. Pharmacokinetics of subcutaneously injected tritiated insulin: effects of exercise. Diabetes 1979, 28 (Suppl. 1): 53-58.

35. Koivisto, V. \& Felig, P. Effects of leg exercise on insulin absorption in diabetic patients. $N$ Engl J Med 1978, 298: 77-83.

36. Koivisto, V.A. \& Felig, P. Alterations in insulin absorption and in blood glucose associated with varying insulin injection sites in diabetic patients. Ann Intern Med 1980, 92: 59-61.

37. Christensen, N.J., Galbo, H., Hansen, J.F., Hesse, B., Richter, E.A. \& Trap-Jensen, J. Catecholamines and exercise. Diabetes 1979, 28 (Suppl. 1), 58-62.

38. Hagenfeldt, L. Metabolism of free fatty acids and ketone bodies during exercise in normal and diabetic man. Diabetes 1979, 28 (Suppl 1): 66-70.

39. Mincu, I., Ionescu-Tirgoviste, C. \& Mihalache, N. The significance of metabolic acidosis recorded during brief muscular exercise in diabetes. In: Berger, M. Christacopoulos, P. \& Wahren, J. (eds) Diabetes and Exercise proceedings of a Symposium. Hans Huber, Bern, 1980, 88.

40. Ploug, T., Galbo, H. \& Richter, E.A. Increased muscle glucose uptake during contractions: no need for insulin. Am J Physiol 1984, 247: E726-E731.

41. Poortmans, J. Saerens, P., Edelman, R., Vertongen, F. \& Dorchy, M. Influence of the degree of metabolic control on physical fitness in Type I diabetic adolescents. Int $J$ Sports Med 1986, 7: 232-235.

42. Berger, M., Berchtold, P., Cuppers, H.-J. et al. Metabolic and hormonal effects of muscular exercise in juvenile type diabetics. Diabetologia 1977, 13: 355-365.
43. Costill, D.L. \& Miller, J.M. Nutrition for endurance sport: carbohydrate and fluid balance. Int J Sports Med 1980, 1: 2-14.

44. Noakes, T. Lore of Running. Cape Town, Oxford University Press, 1986.

45. Felig, P., Sherif, A., Minaguara, A. \& Wahren, J. Hypoglycaemia during prolonged exercise in normal men. $N$ Engl $J$ Med 1982, 306: 895-900.

46. Bergstrom, J., Hermansen, J., Hultman, E. \& Saltir, B. Diet muscle glycogen and physical performance. Acta Physio Scand 1967, 71: 140-150.

47. Maehlum, $S$. Glycogen metabolism and exercise in diabetics. In: Berger, M., Christacopoulos, P. \& Wahren, J. (eds) Diabetes and Exercise - proceedings of a Symposium. Hans Huber, Bern, 1980, pp. 184-188.

48. Horton, E. Clinical implications and limitations of physica training in diabetes. In: Berger, M. Christacopoulos, P. \& Wahren, J. (eds) Diabetes and Exercise - proceedings of a Symposium. Hans Huber, Bern, 1980, 189-193.

49. Ruderman, N.B. \& Haudenschild, C. Diabetes as an atherogenic factor. Prog Cardiovasc 1984, 16: 373-412.

50. Costill, D.L. \& Saltin, B. Factors limiting gastric emptying during rest and exercise. J Appl Physiol 1974, 679-683.

51. Maughan, R.J., Fenn, C.E., Gleeson, M. \& Leiper, J.B. Metabolic and circulatory responses to the ingestion of glucose polymer and glucose-electrolyte solution during exercise in man. Eur J Appl Physiol 1987, 56: 356-362.

52. Scarpello, J.H.B., Barber, D.C., Hague, R.V., Cullen, D.R. \& Sladen, G.E. Gastric emptying of solid meals in diabetes. $\mathrm{Br}$ Med J 1976, ii: 671-673.

53. Pickup, J.C. (ed.) Brittle Diabetes. Blackwell Scientific Publications, Oxford, 1986. 